\title{
INTERFACE ENTRE A ELIPSE E A CIRCUNFERÊNCIA: CONTRIBUTO DA ETNOMODELAGEM NO ENSINO DE GEOMETRIA ANALÍTICA POR MEIO DE CESTARIA
}

\author{
Eliane Costa Santos 1 \\ Ezequias Adolfo Domingas Cassela 2
}

\begin{abstract}
Resumo
Este artigo faz parte de uma pesquisa para o GIEPEm - Grupo Interdisciplinar de Estudos e Pesquisa em Etnomatemática. Apresentamos uma abordagem relacionada ao "descongelamento" da matemática numa dimensão cultural, presente na técnica da construção de dois cestos com bases diferentes, cujo processo de interpretação matemática sugere uma atividade motivacional e significativa no ensino-aprendizagem da Geometria Analítica, com particular realce ao estudo da elipse e da circunferência, baseada no contexto do aluno. As ideias matemáticas extraídas na base de uma vivência com o artesão podem contribuir para a otimização do processo de ensinoaprendizagem na cadeira de Geometria Analítica. Para a metodologia, escolheu-se o enfoque qualitativo, usando a etnomodelagem para a extração dos conhecimentos congelados nos respectivos artefatos, conforme Rosa e Orey $(2010,2018)$. Para o aporte sobre a Geometria Analítica, tomamos como base Cassela $(2018,2020)$; nossa sustentação acerca de artefato sóciocultural de D'Ambrosio (2019) e Gerdes (2011) e, decolonialidade, de Santos (2008, 2018). O resultado matemático apresentado contribui para a decolonialidade do saber, conducente à um possível entendimento, por parte do aluno africano, de que a matemática em sala de aula pode ser tratada a partir dos contexto local.
\end{abstract}

Palavras-chave: Educação Matemática. Etnomodelagem. Geometria Analítica. Artefatos Socioculturais. Decoloniailidade.

\footnotetext{
${ }^{1}$ Doutora em Educação pela Universidade de São Paulo. Docente da UNILAB - Universidade da Integração Internacional da Lusofonia Afro Brasileira e Professora associada da ULAN - Universidade LuejiA'NKonde/Dundo/Angola. Coordenadora do GIEPEm - Grupo Interdisciplinar de Estudos e Pesquisa em Etnomatemática. E-mail: elianecostasantos@unilab.edu.br

${ }^{2}$ Mestre em Matemática para Professores pela Universidade da Beira Interior, Portugal. Docente da ESPB - Escola Superior Pedagógica do Bié /Angola. Membro do GIEPEm - Grupo Interdisciplinar de Estudos e Pesquisa em Etnomatemática. Doutorando da Pontifícia Universidade Católica de São Paulo/Brasil. E-mail: ezequiasadolfo@ hotmail.com
} 
Interface entre a elipse e a circunferência: contributos da Etnomodelagem no ensino de Geometria Analítica por meio da cestaria

\begin{abstract}
This article is part of a research for GIEPEm, which presents an approach related to the unfreezing of mathematics in a cultural dimension, present in the technique of building two baskets with different bases, whose mathematical interpretation process suggests a motivational and significant activity in the teaching-learning of Analytical Geometry, with particular emphasis on the study the ellipse and the circle, based on the student's context. Mathematical ideas extracted on the basis of an experience with the artisan can contribute to the optimization of the teaching-learning process in the subject of Analytical Geometry. For the methodology, the qualitative approach was chosen, using ethnomodeling to extract knowledge frozen in the respective artifacts, according to Rosa and Orey (2010, 2018). For the contribution on analytic geometry, we take as base Cassela (2018, 2020) and our support on socio-cultural artifacts cultural D'Ambrosio (2019), Gerdes(2011); and decoloniality according to Santos $(2008,2018)$. The mathematical result presented contributes to the decoloniality of knowledge, leading to a possible understanding by the African student that mathematics in the classroom can be treated from the local context.
\end{abstract}

Keywords: Mathematical education. Ethnomodeling. Analytical Geometry. Sociocultural artifacts. Decoloniality.

\title{
Introdução
}

O processo de ensino-aprendizagem da Matemática em Angola, como nunca antes, enfrenta determinados desafios. Estes impõem a contextualização dos conteúdos tratados em sala de aulas numa dimensão cultural, uma vez que vai se tornando, cada vez mais notória a preocupação do governo na definição de políticas educacionais que privilegiam a inclusão dos contextos sociais do aluno, com vista a exploração da criatividade cultural do mesmo, direcionada no sentido de se elevar o grau motivacional para a sua aprendizagem, partindo da visão da criação de um clima favorável entorno do estudo da Matemática, com a utilização de recursos disponiveis que fazem parte do contexto sociocultural do aluno.

Esta linha de pensamento tem fundamento na Lei de Bases do Sistema Educativo e Ensino angolano, Lei 17/16 de 7 de outubro, aprovada em 2016 pela Assembleia Nacional da República, alterada e republicada pela Lei n. ${ }^{\circ} 32 / 20$ de 12 de Agosto, conforme se constata na informação 
Interface entre a elipse e a circunferência: contributos da Etnomodelagem no ensino de Geometria Analítica por meio da cestaria

que se segue: “(...) formar um indivíduo capaz de compreender os problemas nacionais, regionais e internacionais de forma critica e construtiva para a sua participação ativa na vida social, à luz dos principios democráticos." (ASSEMBLEIA NACIONAL DE ANGOLA, 2016).

Neste sentido, as escolas devem primar por um processo de ensinoaprendizagem que provoque reflexões nos alunos, de tal forma que se possam elevar, nos mesmos, as capacidades da criatividade, da independência e do raciocínio lógico, com base a resolução de problemas da sua realidade. Para tal, é necessário que o aluno saiba que a matemática surge pela abstração da realidade e que há nexos entre o seu desenvolvimento e o desenvolvimento sociocultural da sociedade, conforme se constata no seguinte argumento de D'Ambrosio (2005 apud CASSELA, 2021, p. 4), quando diz que "o ensino da matemática não deve ser hermético nem elitista. Deve levar em consideração a realidade sociocultural do aluno, o ambiente em que ele vive e o conhecimento que ele traz de casa". Enfatizado por Santos (2014, p. 86), ao trazer que o currículo escolar precisa reconhecer outros modos de pensar matemática do ponto de vista pedagógico: "A matemática escolar rejeita e faz os alunos não aprender várias formas de pensar matemática que são apresentadas na família e na comunidade." Assim, é licito trazer, para sala de aula, olhares que contemplem a cultura africana, visto que "essa cultura negada dentro os espaços escolares, precisam ser visibilizada para contribuir com o ensinoaprendizado." (SANTOS, 2018, p. 12).

Esta ideia é reforçada por vários investigadores que conduziram estudos visando divulgar a existência da matemática em determinadas culturas específicas, como é o caso de Rosa e Orey (2010 apud CASSELA 2021 , p.5), ao afirmarem que

A Matemática é um empreendimento cultural enraizado na tradição. Ela não foi concebida como uma linguagem universal, porque seus princípios, conceitos e fundamentos foram desen- 
Interface entre a elipse e a circunferência: contributos da Etnomodelagem no ensino de Geometria Analítica por meio da cestaria

volvidos de maneira diferenciada pelos membros de grupos culturais distintos.

Em concordância com o descrito anterior, num artigo da Revista Online PRIMUS (2015), dois professores da Universidade Estadual de San Diego, na Califórnia, defendem a integração da arte no programa de uma disciplina de licenciatura de Fundamentos de Geometria. Nos seus argumentos, sublinham que "uma das grandes ambições da Matemática é o visionamento de entidades e espaços intangiveis, mas que se podem expressar por símbolos e aproximações materiais". De realçar que, se poderia manter a clarividência da afirmação, substituindo na frase a palavra matemática pela palavra arte. Entretanto, a perspectiva deste artigo é a de que se deve tirar partido dessa filosofia quando pensamos no ensino da matemática acadêmica, em particular no da Geometria. Tal como na expressão artística, os autores deste artigo concordam que o percurso de Educação Matemática de cidadãos intervenientes numa sociedade global não deve passar pela alienação das suas culturas de origem. Pelo contrário, os contextos culturais podem ser integrados no processo de aprendizagem e melhorar a sua eficácia.

Esta perspectiva requer a matematização ${ }^{3}$ de atividades culturais, fato que levou os autores deste artigo a promoverem um estudo que visa estudar a relação da circunferência e da elipse através de artefatos culturais. As ideias transportadas neste estudo pretendem dar resposta a seguinte questão da pesquisa: que ideias matemáticas estão escondidas em artefatos culturais para o estudo da relação entre a elipse e a circunferência? Por esta razão, este artigo objetiva-se em extrair ideias matemáticas em artefatos culturais com vista a estudar a relação entre a elipse e a circunferência.

\footnotetext{
“A matematização é o processo por meio do qual os membros de diferentes grupos culturais utilizam distintas ferramentas matemáticas que podem auxiliá-los a organizar, analisar, compreender, entender, modelar e resolver situações problemas específicas que são enfrentadas no cotidiano". (ROSA e OREY, 2010 apud CASSELA, 2020, p. 4)
} 
Interface entre a elipse e a circunferência: contributos da Etnomodelagem no ensino de Geometria Analítica por meio da cestaria

Face ao exposto, apresenta-se, em seguida, um breve enquadramento teórico sobre a elipse e a circunferência. Na sequência, faz-se uma abordagem conceitual sobre artefatos culturais, seguindo-se da fundamentação metodológica, onde se apresenta uma síntese referencial inerente a abordagem da pesquisa, técnica ou tipo de análise. Apresenta-se a continuidade a análise e resultados, seguindo-se das considerações finais.

\section{Breve enquadramento teórico sobre a elipse e a circunferência}

Os conteúdos relacionados com a elipse e a circunferência são estudados numa área de conhecimento matemático, denominada Geometria Analítica, a qual, na perspectiva Pickover (2009 apud CASSELA e DE NASCIMENTO, 2020, p. 6), é definida como "o ramo da Matemática que contempla a representação de posições num sistema de coordenadas em que os matemáticos analisam algebricamente essas posições." Do ponto de vista epistemológico, elas são estudadas em diferentes niveis de ensino e são revestidas de capital importância porque a forma das suas curvas permite uma conexão entre os alunos com os seus contextos, cuja abordagem abaixo se apresenta.

\section{Elipse}

Uma elipse é o conjunto dos pontos de um plano cuja soma das distâncias a dois pontos fixos do plano (focos) é constante (figura 1).

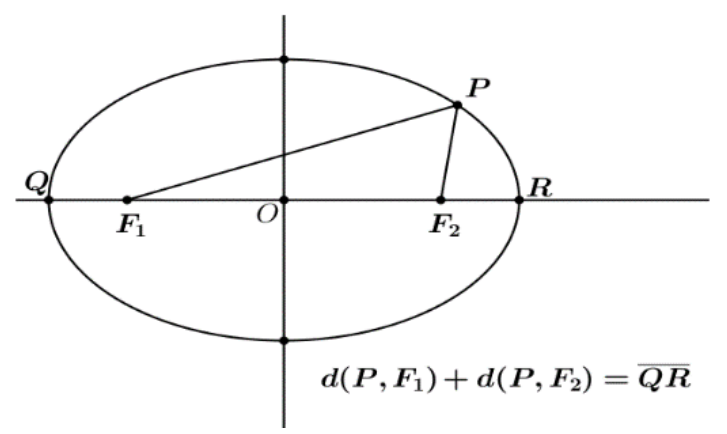

Figura 1 - Representação geométrica da elipse Fonte: Elaborada pelos autores 
Interface entre a elipse e a circunferência: contributos da Etnomodelagem no ensino de Geometria Analítica por meio da cestaria

Considerando um sistema de coordenadas retangulares $X$ e $Y$, no qual está representada uma elipse centrada na origem. Sejam $P(x, y)$ for um ponto arbitrário pertencente a esta elipse, $F_{1}(-c, 0)$ e $F_{2}(c, 0)$, pontos fixos da elipse, posicionados no eixo das abscissas, $A_{1}(-a, 0)$ e $A_{2}(a, 0)$, vértices posicionados no eixo da elipse que contém os pontos $F_{1}$ e $F_{2}$, cujo comprimento é $2 a$. Então, pela definição da elipse, $d\left(P, F_{1}\right)+d\left(P, F_{2}\right)=2 a$, logo, tratando algebricamente esta expressão, obtém-se como resultado o lugar geométrico que satisfaz o conjunto de pontos $P(x, y)$ que é precisamente a equação que se segue:

$$
\frac{x^{2}}{a^{2}}+\frac{y^{2}}{b^{2}}=1
$$

Para uma elipse de focos $(0, \pm c)$ ou $( \pm c, 0)$ e eixo maior de comprimento $2 a$, chama-se excentricidade da elipse a quantidade.

$$
e=\frac{c}{a}
$$

Como $a>c$, a excentricidade é um número compreendido entre $0 \mathrm{e}$ 1: $0<e<1$.

A forma de uma elipse depende do valor da sua excentricidade. Quanto maior for a distância focal de uma elipse, com a fixo, mais a excentricidade se aproxima de 1 e quanto menor for a distância focal, mais a excentricidade se aproxima de 0 . Fazendo variar a excentricidade entre 0 e 1, temos:

- Se $e=0$, isso significa que $c=0, \operatorname{logo} a^{2}=b^{2}$, portanto, os dois focos coincidem com o centro, caso em que a elipse é uma circunferência.

- Se $e=1$ então $c=a$, logo $b^{2}=0$, portanto, nesse caso, não podemos definir a elipse pela equação acima apresentada. Trata- 
Interface entre a elipse e a circunferência: contributos da Etnomodelagem no ensino de Geometria Analítica por meio da cestaria

se do caso em que o gráfico é simplesmente um segmento de reta que une os focos.

\section{Circunferência}

Araújo (2012 apud CASSELA e DE NASCIMENTO 2020, p. 12) apresenta a seguinte definição: A circunferência de centro $O$ e raio $r$ maior que zero, é o lugar geométrico dos pontos do plano que estão a distância $r$ de $O$.

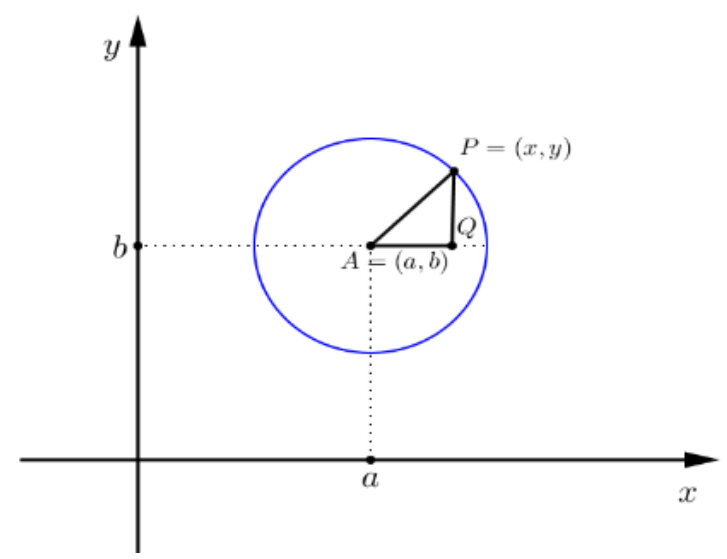

Figura 2 - Representação geométrica da circunferência

Fonte: Cassela e De Nascimento (2020, p. 12)

Na Figura 2 é possível visualizar o triângulo retângulo $\triangle A P Q$, determinando a distância entre o centro $A$ e o ponto $P$ aplicando o Teorema de Pitágoras, obtemos $d^{2}=(x-a)^{2}+(y-b)^{2}$, tomando $d=r$, temos $(x-a)^{2}+(y-b)^{2}=r^{2}$, que é precisamente a equação reduzida da circunferência de raio $r$ e centro no ponto $(a, b)$.

\section{Abordagem conceitual sobre os artefatos culturais}

Na perspectiva de Oliveira (2002 apud CASSELA e AVELINO, 2021), artefatos culturais são objetos feitos pela mão do homem que fornecem 
Interface entre a elipse e a circunferência: contributos da Etnomodelagem no ensino de Geometria Analítica por meio da cestaria

informações sobre a cultura do seu criador e usuários. Segundo Dias (2015, p. 20), "os estudos realizados sobre artefatos no inicio dos anos 70 revelam que os mesmos se envolvem de conhecimentos matemáticos." $\mathrm{Na}$ sequência, o mesmo autor apresenta um argumento que dá indicação das interpretações matemáticas pelos antropólogos ou etnomatemáticos nas técnicas e formas envolvidas nesses artefatos para o campo da educação matemática.

Para Rosa e Orey (2009), os artefatos culturais no processo de ensino-aprendizagem, são instrumentos pedagógicos que podem ser utilizados para facilitar o entendimento e a compreensão no ensino de determinados conteúdos. Associando a este pensamento, o matemático e pesquisador Paulus Gerdes, de origem holandesa, mas vivendo e trabalhando em Moçambique ao longo de mais de três décadas, desenvolveu uma linha de pesquisa baseada no "descongelar" do pensamento geométrico usado para a produção destes artefatos.

A intenção era a de que o investigador inicialmente aprendesse as técnicas de fabricação sobreviventes (por exemplo, as técnicas de entrelaçamento, de produtos de trabalho tradicional como esteiras, cestos, balaios, entre outros) e, em cada fase do processo de fabricação, se questionasse sobre os aspetos de natureza geométrica que desempenham um papel importante para se chegar à fase seguinte, permitindo assim a descoberta do pensamento geométrico escondido. (GERDES, 2012 apud CASSELA, 2018 p. 67).

Nesta perspectiva, os autores deste artigo, escolheram para este estudo dois artefatos culturais que escondem conhecimentos com algum significado geométrico que podem contribuir para a compreensão da relação entre a elipse e a circunferência, que são dois cestos com bases diferentes, um de forma eliptica e, outro, de forma circular, cuja metodologia para a extração destes conhecimentos abaixo se descreve. 
Interface entre a elipse e a circunferência: contributos da Etnomodelagem no ensino de Geometria Analítica por meio da cestaria

\section{Fundamentação metodológica}

Para esta pesquisa, escolheu-se o enfoque qualitativo, privilegiando o emprego de métodos qualitativos de acordo com Cohen, Manion e Morrison (2007 apud DIAS, 2015). Ao longo da recolha de dados, nos servimos da observação participante, do registro de informações derivadas da conversa informal com o artesão, que procurou partilhar as suas experiências no âmbito da produção destes cestos. Foram tiradas algumas fotografias, na medida em que se obtinham as explicações sobre as respectivas técnicas. Para a extração de ideias matemáticas relacionadas com as referidas técnicas, bem como o seu registro, utilizou-se uma "análise descritiva interpretativa", bem como a "etnomodelagem 5 ", onde os artefatos culturais foram tidos como etnomodelos, "considerados como instrumentos pedagógicos utilizados para facilitar o entendimento e a compreensão de sistemas retirados da realidade de grupos culturais distintos". (ROSA e OREY, 2012, p. 870).

\section{Análise e resultados}

Descreve-se inicialmente a conversa informal entre o investigador e o artesão, tendo em conta a ideia original que motivou o artesão a construir os dois cestos. O investigador é denotado pela letra (I) e o artesão pela le$\operatorname{tra}(\mathrm{A})$.

- (I): Qual é a diferença entre a primeira e segunda base?

- (A): Uma é circular e a outra é oval.

- (I): Por que escolheu estas formas?

- (A): A forma circular tem sido a que mais aparece, então, para fazer a diferença, decidi fazer também cestos de forma oval.

\footnotetext{
${ }^{4}$ Aconselhada para estudos etnográficos e para teorias fundamentadas nos dados por Thorne (2016 in CASSELA e AVELINO, 2021 p. 10).

${ }^{5}$ A Etnomodelagem pode ser considerada como o estudo das práticas matemáticas desenvolvidas pelos membros dos grupos culturais distintos por meio da modelagem. (ROSA; OREY, 2012, p. 868).
} 
Interface entre a elipse e a circunferência: contributos da Etnomodelagem no ensino de Geometria Analítica por meio da cestaria

- (I): Como fizeste para definir as duas bases?

- (A): Para a base circular, começo pelo meio fazendo um entrelaçado redondo (ideia do centro) e, com um tipo de capim que tiro na minha aldeia no mês de outubro, depois de seco, entrelaço com linhas de várias cores e envolvo o meio várias vezes até atingir à medida que eu quero. Para a base de forma oval, começo por tirar o capim e entrelaço até ficar direito como um pedaço pequeno de pau (ideia de segmento de reta) e depois vou envolvendo com outro entrelaçado fazendo várias voltas até atingir à medida que eu quero.

\section{Cultural}

\section{Interface entre a elipse e a circunferência: olhar cultural por meio de cestaria}

Comecemos por observar as fotografias abaixo apresentadas que retratam imagens das bases de dois cestos diferentes feitos por um artesão (figura 3).
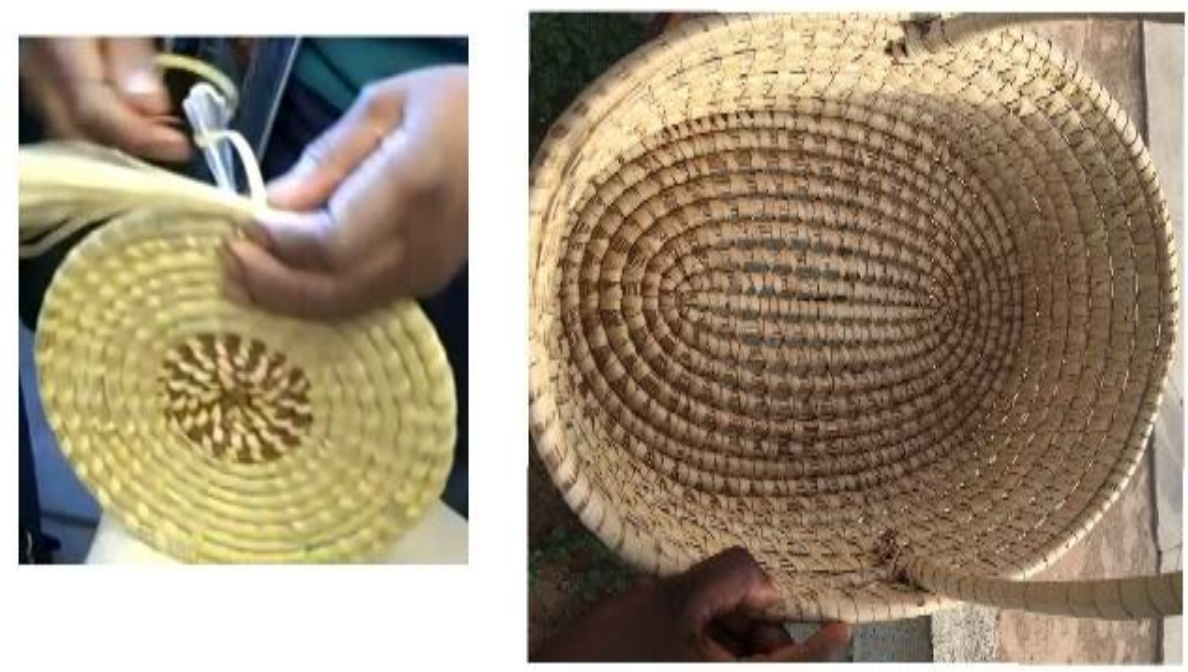

Figura 3 - Bases de cestos (a)

Fonte: Arquivo Pessoal 
Interface entre a elipse e a circunferência: contributos da Etnomodelagem no ensino de Geometria Analítica por meio da cestaria

Seguindo a linha técnica do artesão, marquemos na primeira imagem um ponto $C$, onde ele começa por definir a base. Marquemos também $M$ e $N$, pontos definidos pelo pedaço de pau que, intuitivamente, representa um segmento de reta na segunda imagem.
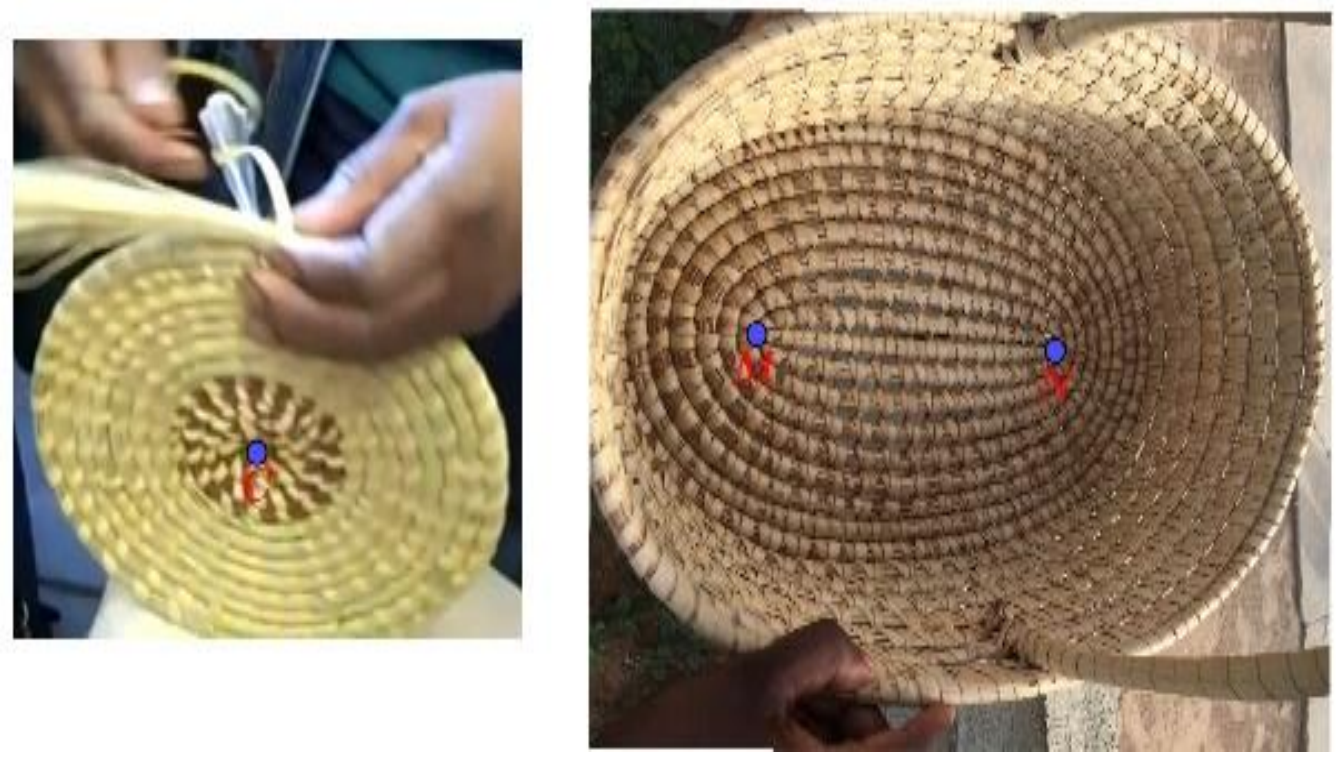

Figura 4 - Bases de cestos (b)

Fonte: Arquivo Pessoal

O ponto $C$ está definido de forma que quaisquer pontos, que possamos imaginar, em cada entrelaçado envolvente terão sempre iguais a distância com respeito a $C-$ com isto, podemos dizer que a primeira imagem tem a forma de uma circunferência com centro em $C$. Se considerarmos o cesto do lado direito (figura 4), vamos ter um segmento de reta $\overline{M N}$ e o artesão, à medida que vai envolvendo este segmento com a forma que ele chama de oval, parece ir descrevendo uma trajetória de pontos cuja soma das distâncias entre o ponto $M$ e o ponto $N$ será uma constante. Se assim for, podemos dizer que os vários contornos, observados na segunda figura, têm a forma de uma elipse com focos em $M$ e $N$. 
Interface entre a elipse e a circunferência: contributos da Etnomodelagem no ensino de Geometria Analítica por meio da cestaria

Da técnica do artesão, podemos interpretar a diferença entre a circunferência e a elipse, para tal comecemos por analisar a segunda imagem.

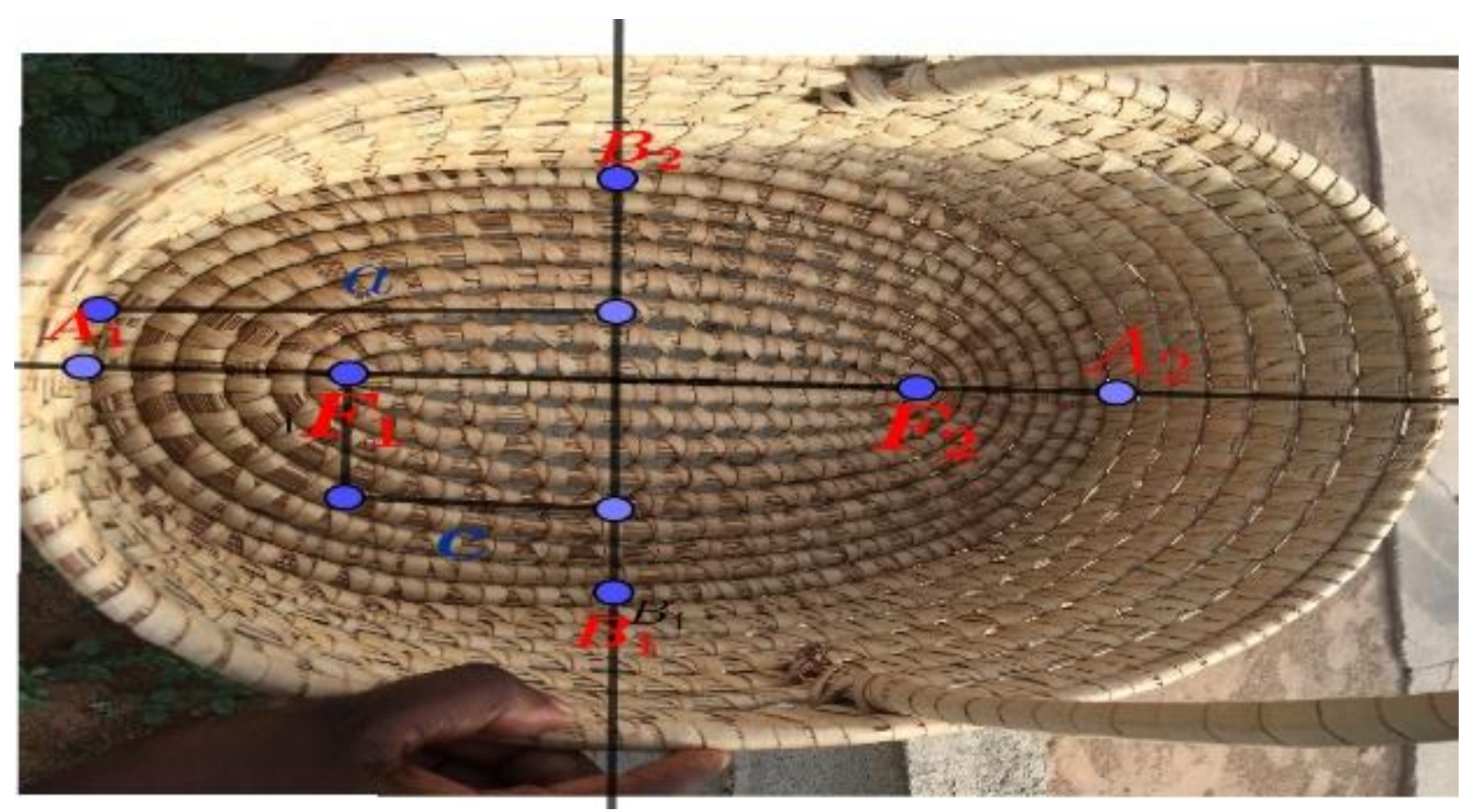

Figura 5 - Cesto elíptico

Fonte: Arquivo Pessoal

Observa-se que as voltas que o artesão vão dando ao segmento de

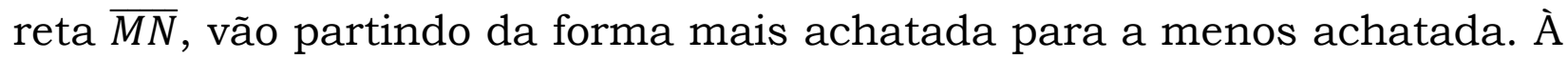
medida que a curva vai se tornando cada vez menos achatada, vai sendo maior a diferença de comprimentos entre os segmentos $\overline{F_{1} F_{2}}$ (onde $F_{1}=M$ e $F_{2}=M$ são os focos da elipse) e $\overline{A_{1} A_{2}}$ (eixo maior da elipse). Se o artesão continuar, vai obter uma curva cada vez mais próxima da circunferência. Matematicamente, existe um número compreendido entre 0 e 1 que traduz estas transformações na elipse que é a chamada excentricidade de elipse (razão entre a metade da distância focal e o semi-eixo maior). Por- 
Interface entre a elipse e a circunferência: contributos da Etnomodelagem no ensino de Geometria Analítica por meio da cestaria

tanto, a circunferência pode ser considerada como a elipse de excentricidade nula conforme a figura 6.

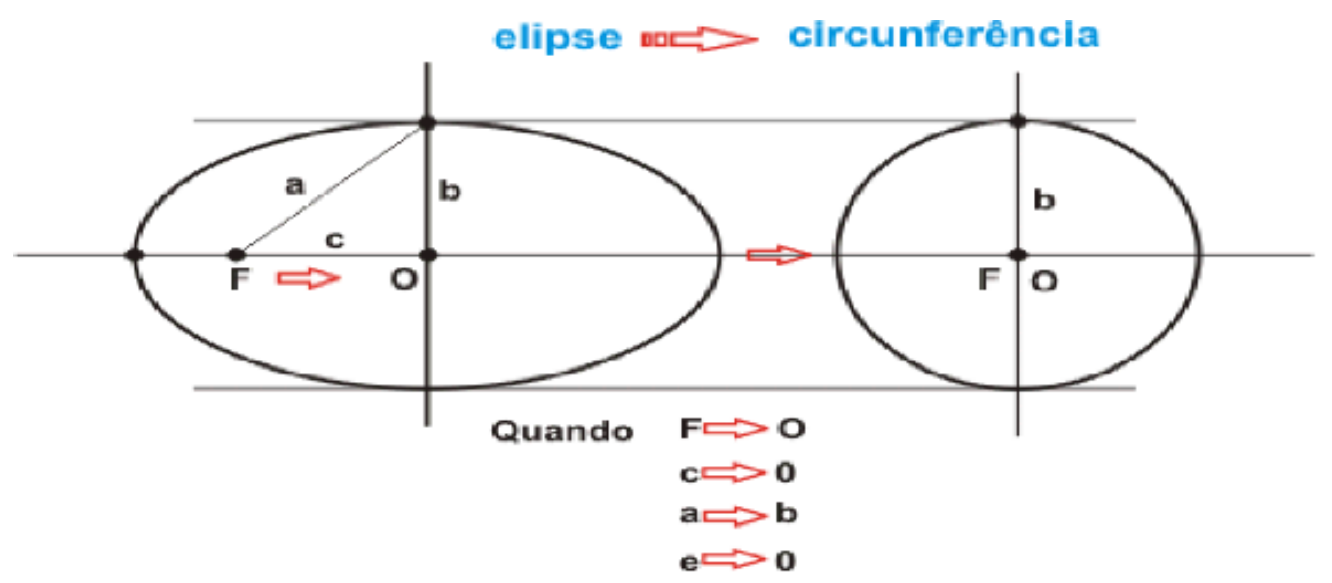

Figura 6 - Relação entre uma elipse e uma circunferência

\section{Considerações finais}

As ideias apresentadas neste artigo dão conta de uma matemática em uma dimensão cultural congelada em dois artefatos culturais cujo processo de interpretação matemática sugere uma atividade motivacional e significativa no ensino-aprendizagem da Geometria Analitica, com particular realce ao estudo da elipse e da circunferência, baseada no contexto do aluno.

O resultado matemático apresentado aponta a possibilidade de ao trazer um artefato cultural para a sala de aula, mobiliza o mentefato, contribuindo de forma significativa para a quebra epistemológica de um "saber para poucos", e de "uma única vertente abstrata", dada por meio de um cálculo formularizado sem contextualização.

Em especial, o cesto elíptico matematizado, visibiliza um conhecimento de artesãos de Angola, quiçá de vários países do continente africano, possibilitando aos estudantes outros caminhos de aprendizagem, sem 
Interface entre a elipse e a circunferência: contributos da Etnomodelagem no ensino de Geometria Analítica por meio da cestaria

negar a educação escolar, mas também sem sustentar a dicotomia da educação eurocêntrica que não permite saberes que sejam de outras culturas, conduzindo a um possivel entendimento por parte do aluno, que a Matemática não é algo estranho, distante, importada de fora de África.

A relevância desse artigo está em trazer para os alunos a possibilidade destes, identificarem outros "problemas" semelhantes nos seus contextos e resolvê-los utilizando o mesmo procedimento. Os resultados encontrados estão dirigidos de modo a dar resposta ao problema da pesquisa. A metodologia usada permitiu a eficácia dos procedimentos para a recolha da informação necessária nas autoridades tradicionais.

\section{Referências}

ARAÚJO, Paulo Ventura. Curso de Geometria. Lisboa:Gradiva, 2012.

CASSELA, Ezequias Adolfo Domingas e DE NASCIMENTO, Rosa Maria. Estudo da circunferência à luz dos princípios axiomáticos de René Descartes. Um olhar ao contexto de ensino-aprendizagem da Escola Superior Pedagógica do Bié. REVEMAT, v. 15, p. 1-21, 2020.

CASSElA, Ezequias Adolfo Domingas. Ensino da Geometria Analítica no contexto cultural do Cuito/Bié. (Dissertação de Mestrado em Matemática para professores). Universidade da Beira Interior, Covilhã, Portugal, 2018.

CASSElA, Ezequias Adolfo Domingas; AVELINO, Pedro Chimbinda. Artefatos socioculturais do Cuito/Bié-Angola para o Ensino da Geometria - a circunferência numa perspectiva da Etnomatemática. REVEMAT, v. 16, p. 1-22, 2021.

CASSELA, Ezequias Adolfo Domingas. A Matemática escondida na arte de enrolar e desenrolar lenços nas cabeças das mulheres angolanas. Um recurso didáctico para aprendizagem da função seno e da sua inversa. European Review of Artistic Studies, v. 1, n.11, p. 1-14, 2020.

CASSELA, Ezequias Adolfo Domingas. Da Matemática nativa presente no pensamento das autoridades tradicionais da tribu umbundu com respeito a forma do ondjango no Cuito/Bié-Angola para problemas isoperimétricos da Geometria Plana. European Review of Artistic Studies, v. 11, n.2, p. 69-80, jun. 2020. 
Interface entre a elipse e a circunferência: contributos da Etnomodelagem no ensino de Geometria Analítica por meio da cestaria

COHEN, Louis; MANION Lawerence; MORRISON, Keith. Reseach Methods in Education. London: Routledge, 2007.

D'AMBROSIO, Ubiratan. Etnomatematica - Elo entre as tradições e a modernidade. 6. Ed. Belo Horizonte: Autêntica, 2019.

DIAS, Domingos. Estudos etnomatemáticos sobre o grupo étnico NyanecaNkhumbi do Sdoeste de Angola. Aplicações à Educação Matemática. Tese (Doutorado) - Universidade do Minho, Portugal, 2015.

GERDES, Paulus. Mulheres, cultura e geometria na África Austral. Maputo, Mocambique: Centro Moçambicano de Pesquisa Etnomatemática, 2011.

ROSA, Miltone OREY, Daniel Clark. O campo de pesquisa em etnomodelagem: as abordagens êmica, ética e dialética. Educação e Pesquisa, 38(4), p. 865879, 2010.

ROSA, Miltone OREY, Daniel Clark. O campo de pesquisa em etnomodelagem: as abordagens êmica, ética e dialética Educação e Pesquisa, São Paulo, v. 38, n. 4, p.865-879, out./dez; 2012.

SANTOS, Eliane Costa. As ticas da matema de algumas etnias africanas: suporte para a decolonialidade do saber. Revista da Associação Brasileira de Pesquisadores/as Negros/as ABPN, v. 10, p. 88-112, jan. 2018.

Disponivel em:

http://www.abpnrevista.org.br/revista/index.php/revistaabpn $1 /$ article/view / 5 31. Acesso em: 3 mar 2021.

SANTOS, Eliane Costa. Para além dos números... África e africanidade na formação de professores: enfoque etnomatemático para uma reorientação educacional. Tese (Doutorado em Educação) - Universidade de São Paulo, São Paulo, 2014.

SANTOS, Eliane Costa. Os tecidos de Gana como atividade escolar: uma intervenção etnomatemático para a sala de aula. DISSERTAÇÃO (Mestrado em Educação Matemática) - Pontificia Universidade Católica de São Paulo, São Paulo, 2008.

Disponivel em: https://sapientia.pucsp.br/handle/handle/11295. Acesso em: 3 mar 2021. 